\title{
Diversity and Inclusion in Conservation: A Proposal for a Marine Diversity Network
}

\author{
Nicola S. Smith ${ }^{1}$, Isabelle M. Côté ${ }^{1}$, Lourdes Martinez-Estevez ${ }^{2 *}$, Edward J. Hind-Ozan ${ }^{3}$, \\ Angela L. Quiros ${ }^{2}$, Nathan Johnson ${ }^{4}$, Stephanie J. Green ${ }^{5}$, Leslie Cornick ${ }^{6}$, \\ David Shiffman ${ }^{1}$, Luis Malpica-Cruz ${ }^{1,7}$, Allison Gleason Besch ${ }^{8}$ and Nikita Shiel-Rolle ${ }^{9}$ \\ ${ }^{1}$ Earth to Ocean Research Group, Department of Biological Sciences, Simon Fraser University, Burnaby, BC, Canada, \\ ${ }^{2}$ Coastal Conservation Action Laboratory, Department of Ecology and Evolutionary Biology, University of California, Santa \\ Cruz, CA, United States, ${ }^{3}$ Sustainable Places Research Institute, Cardiff University, Wales, United Kingdom, ${ }^{4}$ Speak Up For \\ Blue, Galveston, TX, United States, ${ }^{5}$ Center for Ocean Solutions, Stanford University, Monterey, CA, United States, \\ ${ }^{6}$ Department of Marine and Environmental Sciences, Alaska Pacific University, Anchorage, AK, United States, ${ }^{7}$ ECOCIMATI, \\ AC, Ensenada, Mexico, ${ }^{8}$ Nicholas School of the Environment, Duke University, Durham, NC, United States, ${ }^{9}$ Young Marine \\ Explorers, Nassau, Bahamas
}

\section{OPEN ACCESS}

Edited by:

Ellen Hines,

San Francisco State University,

United States

Reviewed by:

Joshua Adam Drew,

Columbia University, United States

Samantha Oester,

George Mason University,

United States

Silvana Noemi Raquel Birchenough, Centre for Environment, Fisheries and Aquaculture Science, United Kingdom

*Correspondence:

Lourdes Martinez-Estevez

mmarti72@ucsc.edu

Specialty section:

This article was submitted to Marine Conservation and

Sustainability,

a section of the journal

Frontiers in Marine Science

Received: 14 March 2017

Accepted: 11 July 2017

Published: 02 August 2017

Citation:

Smith NS, Côté IM, Martinez-Estevez L, Hind-Ozan EJ, Quiros AL, Johnson

N, Green SJ, Cornick L, Shiffman D, Malpica-Cruz L, Gleason Besch A and

Shiel-Rolle N (2017) Diversity and Inclusion in Conservation: A Proposal for a Marine Diversity Network

Front. Mar. Sci. 4:234 doi: 10.3389/fmars.2017.00234
Low diversity among scientists and practitioners is rampant in conservation. Currently, conservation professionals do not reflect the same diversity of perspectives and experiences of the world as the communities who bear the largest burden for implementing - or adverse consequences for failing to implement-conservation action. Acknowledging and describing the problem is important. But policies and programmes must also be put in place to correct it. Here, we highlight some measurable benefits of workforce diversity, and give an overview of some of the barriers to inclusion in marine conservation that help perpetuate low workforce diversity. Importantly, we underscore actions that both individuals and groups can take to alleviate such barriers. In particular, we describe the establishment of an online Marine Diversity Network, which conference participants proposed during a focus group meeting at the 4th International Marine Conservation Congress. The network will serve to bring together people from across the globe, from a variety of backgrounds, and from all career stages, to share knowledge, experiences and ideas, to provide and receive mentorship in marine conservation, and to forge new collaborations. Removing barriers to diverse participation requires coordinated, mindful actions by individuals and organizations. We hope that the proposed network and other actions presented in this paper find widespread support, and that they might serve both as inspiration and guide to other groups concerned with increasing diversity and inclusivity.

\section{Keywords: barriers to inclusion, diversity in science, marine conservation, online communities, online network}

\section{OVERVIEW}

Recent calls to address low diversity among scientists and practitioners in conservation and related disciplines have been varied and numerous (e.g., Pearson and Schuldt, 2014; Tallis and Lubchenco, 2014; Taylor, 2014; Green et al., 2015; Arismendi and Penaluna, 2016). As with any societal concern, acknowledging and describing the problem is important. But this is just the first step. Policies and programmes must also be put in place to correct it and organizations must be held accountable for low workforce diversity. We agree with Arismendi and Penaluna (2016) that 
"because diversity has been systematically underrepresented, we likely need to consider additional ways to systematically include it." Here, we outline one attempt by the Society for Conservation Biology Marine Section (SCB Marine Section) to address the problem of low workforce diversity and foster inclusion in marine conservation, which can be used as a model for other groups. Conference participants discussed the issue during a focus group meeting at the 4th International Marine Conservation Congress (IMCC4) in 2016 in St. John's, NL, Canada. The result is a proposed marine diversity network, which we describe here.

\section{THE DIVERSITY CRISIS IN CONSERVATION}

Most conservation scientists, educators, and practitioners are familiar with the concept of diversity. It has multiple dimensions that can be easily measured-i.e., variety, balance, and disparity (Stirling, 2007; Box 1) - and can be applied to both human and non-human systems.

By all measures, low workforce diversity is rampant in conservation (Taylor, 2014), fisheries (Arismendi and Penaluna, 2016), forestry (Kern et al., 2015), and climate (Pearson and Schuldt, 2014) sciences within academic institutions and organizations founded or based in North America and Europe. These fields, like many others in science, suffer from a diversity crisis (Pearson and Schuldt, 2014). Most attention to the problem-and progress - to date has focused on issues surrounding gender inequality (e.g., Steinpreis et al., 1999; Murphy et al., 2007; Ceci and Williams, 2011; Martin, 2012; Moss-Racusin et al., 2012; Cho et al., 2014; Reuben et al., 2014; Taylor, 2014; Conti and Visentin, 2015; Kern et al., 2015; Arismendi and Penaluna, 2016). But there is also a paucity of representation by people from different races and ethnicities (Ginther et al., 2011; Pearson and Schuldt, 2014; Taylor, 2014; Arismendi and Penaluna, 2016), socioeconomic backgrounds (Taylor, 2014; Laurison and Friedman, 2016), geographic regions (Burgman et al., 2015; Meijaard et al., 2015), and other groupings.

The mainstream conservation movement in the United States, for example, is dominated by white, upper middle-class Americans (Taylor, 2014). In one of the most comprehensive studies to date, Taylor (2014) critically examined workforce diversity in 191 conservation and preservation organizations, 74 governmental environmental agencies, and 28 environmental grant-making foundations in the U.S. Her findings highlight an uncomfortable truth: the demographic composition of most U.S. environmental institutions does not reflect that of the country as a whole. Although, people of color make up 38\% of the U.S. population and constitute $29 \%$ of the workforce in science and engineering, they encounter what has been called a "green ceiling" where non-white minorities do not exceed $16 \%$ of staff in environmental institutions (Taylor, 2014). Furthermore, the few people of color within these institutions rarely hold leadership positions (Taylor, 2014). The same can be said for the underrepresentation of women in leadership positions in U.S. conservation organizations, in which $70 \%$ of the presidents and board chairs are men (Taylor, 2014).
What about diversity within international, professional conservation societies such as the SCB Marine Section? In 2016, the SCB Marine Section had 819 members from 68 countries-a statistic that suggests respectable geographic diversity. However, almost three-quarters of its members (i.e., 596 people or $72.8 \%$ ) were affiliated with institutions based in just four wealthy nations: the U.S., Canada, the United Kingdom and Australia (Figure 1). Almost half of all members (47.5\%) were affiliated with U.S. institutions (Figure 1). The remaining 27\% of members were affiliated with institutions from 64 countries, with most countries represented by fewer than five members (Figure 1). Unfortunately, lack of data prevents us from assessing diversity within the Section by other pertinent measures such as race, socioeconomic background, or even gender.

\section{WHY STRIVE FOR DIVERSITY?}

Just like ecological diversity is associated with a range of favorable environmental and economic consequences (Pimentel et al., 1997), there are measurable benefits of diversity in the workforce and in science endeavors. Østergaard et al. (2011) found a positive association between the likelihood of innovation within an organization and employee diversity in gender and education. Freeman and Huang (2015) revealed that greater diversity in manuscript co-authors increased the likelihood that a paper would have a high impact on science in terms of journal impact factor and number of citations. Summarizing the findings from numerous studies, Wullum Nielsen et al. (2017) showed that gender diversity can result in "better science"-described in terms such as broader scientific insights-when it occurs within a supportive institutional context (e.g., non-hierarchical structures where individuals from underrepresented groups attain a "critical mass" of between 15 and $30 \%$ of team members).

Ultimately, effective conservation solutions must consider the local contexts and values of the communities who are undertaking the actions. Currently, conservation professionals do not reflect the diversity of perspectives and experiences of the world as the communities who bear the largest burden for implementing-or adverse consequences for failing to implement-conservation action (Romero and Andrade, 2004). Conservation professionals without appropriate cultural values and contexts are unlikely to develop effective or appropriate solutions (see also Douglas and Veríssimo, 2013; Green et al., 2015). By failing to involve people from diverse backgrounds, we run the risk of isolating the goals and activities of conservation from wider society, which can lead to decreased public support for conservation. A growing body of literature, for instance, illustrates how local citizens engaging in science can increase stakeholder willingness to support and participate in activities that conserve local biodiversity (e.g., Evans et al., 2005; Cooper et al., 2007).

\section{BARRIERS TO INCLUSION}

Inclusion can be described as "welcoming and including a diverse range of people, and having their input and perspectives valued 


\section{BOX 1 | Dimensions of diversity}

We must be equally as rigorous in our assessment of workforce diversity within conservation organizations as we are in our assessment of biological diversity within ecological communities. There are three distinct dimensions to diversity, which are common among disciplines: variety, balance, and disparity (Stirling, 2007).

Variety refers to the number of different types of categories that a group contains. It is the ecological equivalent of species richness (Stirling, 2007). Unfortunately, there is sometimes a tendency to limit assessments of diversity within an organization to this single property, leading to tokenism, i.e., when there is a single representative of a particular group.

Balance refers to the distribution of things across categories. It is the ecological equivalent of species evenness (Stirling, 2007). Many studies on workforce diversity are concerned with balance in terms of the proportions of people represented by particular groups within an organization vs. the proportions of people represented by particular groups within larger society (e.g., national demographics).

Disparity refers to the degree of distinctiveness or difference among categories within a group (Stirling, 2007). It is the evolutionary equivalent of phylogenetic distance among taxa on a phylogenetic tree. In our experience, few studies have examined disparity within an organization.

We assert that all three dimensions of diversity should be considered when evaluating the diversity of scientists, educators, and practitioners within marine conservation.

and considered within the context of a collective endeavor" (Bonta et al., 2015). Inclusion pertains to the "process and culture" of an organization (Bonta et al., 2015). It is a way of thinking and doing things within a group.

There are numerous barriers to inclusion in marine conservation, which help perpetuate low workforce diversity. In particular, significant social hurdles (e.g., gender, economic, systemic, and/or implicit institutional biases) persist in many countries to entering science careers in general, and conservation science careers in particular (Steinpreis et al., 1999; Ginther et al., 2011; Taylor, 2014; Laurison and Friedman, 2016). For example, many field assistant positions in wildlife ecology and conservation-which provide valuable experience that can improve a student's chances of being admitted to a graduate program or secure research funding-offer little or no pay (Fournier and Bond, 2015). These positions can therefore be accepted only by people with fewer financial constraints, limiting future workforce diversity in the field (Fournier and Bond, 2015). For many who do achieve careers in conservation, the barriers to accessing professional resources can be numerous and profound. These issues include, among others, the predominance of English as the language of science (Amano and Sutherland, 2013; Giehl et al., 2017), publishing practices that restrict access to knowledge behind paywalls (Fuller et al., 2014; Giehl et al., 2017), and the red tape associated with international travel to attend training or conferences. Wilson and Biggs (2016), for example, found that $34 \%$ of scientists from developing countries reported forfeiting professional opportunities due to visa delays or denials, despite spending more than $10 \mathrm{~h}$, on average, on visa applications. In contrast, scientists from developed countries did not perceive current visa regulations as a significant barrier to professional travel (Wilson and Biggs, 2016).

\section{ACTIONS TOWARD A SOLUTION: WHAT INDIVIDUALS CAN DO}

Individuals can play a role in alleviating barriers to inclusion in marine conservation. We highlight three areas for action, among the many that could be undertaken.

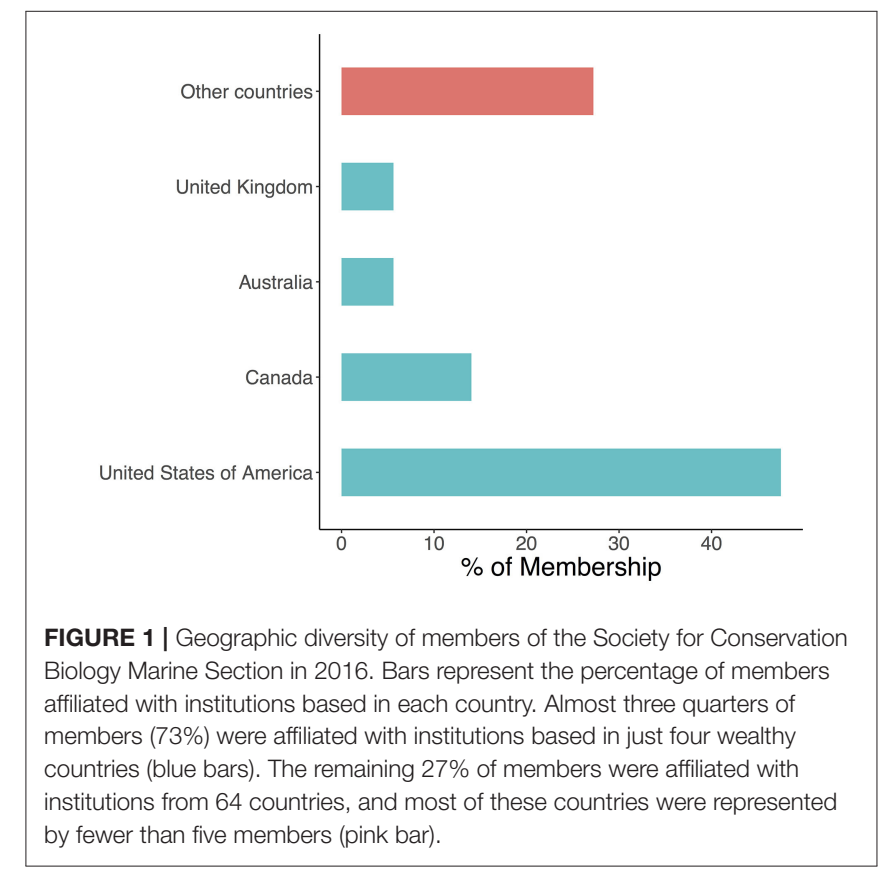

\section{Empower and Engage Youth from Underrepresented Groups}

There are many ways to empower and enthuse young people from underrepresented groups to become conservation professionals. Contact with "real-life" conservation scientists can demystify both the science and the people doing it. These contacts can be made face-to-face-e.g., similar to Soapbox Science, a public outreach platform for promoting women scientists and their science internationally (soapboxscience.org) - or via digital means. For example, there are many "skype-a-scientist" programs that bring scientists to distant classrooms at minimal cost (e.g., Heenehan, 2014).

\section{Increase Access to Professional Resources}

Individuals can work to reduce barriers to accessing professional resources. Researchers can elect to publish their most relevant work in open-access journals or pay for open access in 
subscription journals (Fuller et al., 2014). This is the rationale for making the proceedings of IMCC4 open access. We acknowledge, however, that open-access publishing may not be possible for researchers who cannot afford publication fees. Individuals can also disseminate their findings to a broader audience by writing blogs, press releases and other "popular" articles with translations in non-English languages (Primack, 2001), and by posting videos online and using social media (e.g., Twitter) to share messages from conferences (Parsons et al., 2014). Even helping with rigid visa rules is possible. As part of a larger diversity initiative during IMCC4, conference organizers set up a formal system in which Section members volunteered to assist wouldbe conference goers with visa applications. Efforts were also made at IMCC4 to attract delegates from diverse geographies by distributing meeting marketing materials and accepting abstracts in different languages (for details see http://conbio.org/minisites/imcc-2016/about/imcc-for-all/).

\section{Promote Career Advancement of Individuals from Underrepresented Groups by Being Aware of Bias}

Mid- and late-career professionals can help break down barriers to advancement for individuals from underrepresented backgrounds by being conscious of bias in the supportive activities they take on. This includes writing bias-free letters of reference (Madera et al., 2009), and nominating these colleagues for awards, to give plenary addresses, and to take part in workshops and various specialized training. Sardelis and Drew (2016) found that having women as symposium organizers increased the number of female speakers at the event. Conference organizers could therefore add a stipulation that a certain percentage of accepted symposia have to include an organizer from an underrepresented group.

\section{ACTIONS TOWARD A SOLUTION: A MARINE DIVERSITY NETWORK}

Ecological and environmental societies have a variable record of concern and engagement with the issue of diversity (Box 2). Some of the more established activities focus on mentorship at annual conferences. IMCC4 participants discussed the problem of low workforce diversity and inclusion in marine conservation during a focus group meeting. Their agreed first step on the road to a solution was proposing something different: the establishment of an online-based Marine Diversity Network $(\mathrm{MDN})$, which we outline here as a potential model for other groups seeking to become more diverse and inclusive.

\section{Mission}

The mission of the MDN is to create a collaborative, online network that focuses on issues in marine conservation, and comprises diverse scientists, educators, and practitioners. The network will serve to bring together people from across the globe, from a variety of backgrounds, and from all stages of career development, to share knowledge, experiences and ideas, and to provide and receive mentorship. Ideally, such a network
BOX 2 | Actions to promote diversity: What have other groups done? A brief survey of ecological, environmental and conservation societies in North and South America, Europe, and Oceania, reveals a wide spectrum of actions undertaken to address the diversity crisis. These actions range from differential membership fees that are lower for students and early career scientists (most societies), to published Diversity Statements (some, all very recent), the creation of Working Groups and Committees to address diversity issues (fewer), and specific programs to address the problem (fewer still). We highlight here the diversity programs of three professional societies to illustrate the variety of approaches to a shared concern.

1. Association for the Sciences of Limnology and Oceanography (ASLO)

ASLO has been building ethnic diversity through its flagship Multicultural Program (ASLOMP; http://www.aslo.org/mas) since 1990. The aim is to create cohorts of informed and connected students from underrepresented groups. Each cohort meets 2 days before the start of the annual ASLO conference. Students participate in fieldtrips and workshops on career and skills development, and attend talks by professional role models. Students are then assigned "meeting-mentors," ASLO members who volunteer their time to mentor students throughout the meeting, and attend all social events. Many ASLOMP students also present their research in a special symposium. More than 700 students from over 150 different institutions have participated in the program so far.

\section{British Ecological Society (BES)}

The BES created an Equality and Diversity (E\&D) Task Group in 2015, which made a set of recommendations. Twelve were implemented the following year (http://www.britishecologicalsociety.org/about/diversity-andthe-bes), demonstrating that much progress can be achieved in short order. These included:

- Establishing a Working Group to develop and oversee the delivery of the Society's E\&D work

- Developing and publishing an E\&D statement

- Collecting E\&D data on membership

- Launching and awarding the first Equality and Diversity Champion prize

- Writing regular E\&D features in the Society's newsletter

- Introducing E\&D guidelines for committees and working groups

- Developing a code of conduct for BES conferences

- Including E\&D criteria in the selection of Annual Meeting proposals

- Reviewing the recruitment process and introducing unconscious bias training for paid and unpaid positions

\section{Ecological Society of America (ESA)}

The ESA has operated a mentorship program called SEEDS (Strategies for Education in Ecology, Development, and Sustainability) since 1996 (esa.org/seeds). The purpose of SEEDS is to increase the representation of historically underrepresented minority groups within the ecological sciences. Early efforts focused on Historically Black Colleges and Universities, working through partners at the United Negro College Fund, but the program has since expanded to include other underrepresented groups. SEEDS focuses primarily on undergraduates, but there are spin-off programs targeting adults and younger students from underrepresented minority communities. SEEDS offers travel scholarships to the ESA annual meeting, and provides a mentor and guide to answer students' questions at the conference. SEEDS also organizes (and covers the costs of) educational field trips designed to expose students of all backgrounds to nature from the perspective of ecological study.

would help to build equitable relationships among diverse groups of people that lead to future collaborative work in marine conservation (see Hind et al., 2015 for a guide to international collaborations). The network will extend beyond SCB Marine 
Section members and be open to anyone engaged in the practice or study of marine conservation. Furthermore, membership to the MDN will be free, potentially increasing diverse participation otherwise limited by financial hurdles. In these ways, the MDN will help to promote diversity-in terms of geographic regions, cultures, expertise, employment paths, and career stages-and inclusion in marine conservation.

\section{Goals}

The IMCC4 participants identified three main goals of the MDN.

\section{Connect People and Organizations}

The MDN aims to connect people and organizations that share similar interests in marine conservation but that do not necessarily share similar backgrounds or expertise and thus, have a low likelihood of interacting. To achieve this, MDN members will contribute their profile information to a public repository, i.e., the "Marine Conservation Collective." Profiles will contain a photo of the member, brief description of their specific interests and expertise in marine conservation, the region of the world in which they work, and some form of contact information (e.g., an email address). The IMCC4 participants also proposed to create (and maintain) a repository of web links to organizations, agencies, cooperatives, and other existing networks that specialize in issues related to marine conservation. Ideally, MDN members and marine conservation entities will be searchable on the network by key words or phrases (e.g., "marine protected areas," "ecological economics," "policy," or "citizen science"), or by geographic regions.

\section{Exchange Knowledge, Experiences, and Ideas}

The MDN aims to provide a safe and welcoming online environment for the exchange of knowledge, experiences, and ideas in marine conservation. The creation of a discussion board, i.e., the "Blue Board," on the network site is one way to achieve this goal. MDN members will be able to use the discussion board to initiate conversations on any marine conservation-related topic. Additionally, the MDN can host scheduled discussions on a regular basis on topics that are of interest to network users. Discussions will be grouped by topic and archived on the network for future reference. The MDN will have a code of conduct (e.g., see IMCC4 Code of Conduct; Favaro et al., 2016) to ensure that all discussions are conducted in a professional and civil manner. Anyone who wishes to participate in the MDN will have to sign this code of conduct. A network administrator will moderate conversations on the discussion board, and remove comments that do not comply with the code of conduct.

\section{Provide and Receive Mentorship}

A final goal of the MDN is to create the opportunity for its members to provide and receive short-term mentorship or assistance in areas related to marine conservation. We propose a program called "Mentor for a Month." This program will encourage members to assist one another on a short-term basis on projects related to marine conservation. As part of this program, MDN members will be able to indicate on their network profile page whether they are interested in serving as a mentor.
A simple means of doing so will be to have an icon (e.g., a check mark) next to each member's name, with color indicating that an individual is willing to act as a mentor during a period that can be specified. This opens the door for a potential mentee to contact a potential mentor. However, both mentor and mentee reserve the right to decline to work with one another, or to terminate a relationship early. For example, suppose a MDN member were the head of a small non-governmental organization (NGO) that focuses on ocean issues. The head of this NGO might want to run a short marketing campaign to raise awareness about dumping at a popular beach. Since they may not be an expert on conservation marketing, they may wish to search MDN member profiles for people with this knowledge and experience willing to act as a mentor for a month. They can then contact the potential mentor and pitch a proposal for mentorship.

\section{WHERE DO WE GO FROM HERE? QUICK GUIDE TO CREATING AN ONLINE NETWORK}

There are at least six key steps to making the MDN a reality, which can be broadly applied to other online networks.

\section{Determine Network Form}

Networks can have various forms. For the MDN, we envisage an internet-based environment that requires membership to participate. Other attributes of networks, however, must be considered such as whether it will be private vs. public, small vs. large, commercial vs. non-commercial, and whether membership will be free or not (Notley, 2009).

\section{Create Network Hub}

A website or similar platform (e.g., Facebook or Twitter account) must be created to act as the hub of the network. In the case of the MDN, conference participants suggested that a web page could be paired with an app with offline capabilities. Such an app would be necessary because the online nature of the network might represent a technological challenge to participation for members based in remote locations without reliable Internet access.

\section{Secure Sustainable Funding}

Most online networks require sustained funding to build, maintain, and continually upgrade the hub. Marine conservation initiatives, including online networks, tend to fail in the long term when they receive a one-time injection of equity (Hind et al., 2015). Given that free membership is essential to the MDN's mission of alleviating barriers to participation, self-funding is not an option. Funds to create and maintain the MDN and similar online networks might be obtained through multiple sources, including donations, grants, corporate sponsorships, fundraising events, and crowdfunding.

\section{Establish a Founding Membership}

Fledgling networks require a founding membership who actively support and promote their mission and work. In terms of the MDN, we envisage a committee of volunteers that will administer the network and serve for fixed terms, along with a part-time 
paid position for someone with expertise in forming online communities who would perform particularly complex and timeconsuming tasks.

\section{Identify and Track Quantifiable Measures of Success}

To ensure accountability and transparency, networks should have quantifiable measures of success. Key metrics could include: (1) number of members, (2) number of groups (e.g., countries) represented by network members and their relative distribution and, (3) number and frequency of interactions among network members. In the case of the MDN, the number of members and frequency with which they participate in discussions on Blue Board could be important metrics of success.

\section{Host an Official Launch Event}

Hosting an official launch event is an effective way to bring exposure and generate excitement about the network to a target audience. The timing, location, and audience for the event should be carefully considered. Also, if the network has multiple features, such as proposed for the MDN (i.e., a public repository, a discussion board, and a mentorship program), one should consider whether to host a single event after all features are developed or several events as features are developed in phases. Making launch events coincide with a major gathering of interested parties is an effective strategy. The SCB Marine Section Diversity Committee, for example, is targeting the 5th International Marine Conservation Congress (IMCC5) as a launch platform for the MDN.

\section{CONCLUSION}

There are many ways to increase member diversity in an organization, and many good reasons to do so. Removing

\section{REFERENCES}

Amano, T., and Sutherland, W. J. (2013). Four barriers to the global understanding of biodiversity conservation: wealth, language, geographical location and security. Proc. R. Soc. B 280:20122649. doi: 10.1098/rspb.2012.2649

Arismendi, I., and Penaluna, B. E. (2016). Examining diversity inequities in fisheries science: a call to action. Bioscience 66, 584-591. doi: 10.1093/biosci/biw041

Bonta, M., DeFalco, T., and Taylor Smith, C. (2015). Diversity and the Conservation Movement. New York, NY: National Audubon Society.

Burgman, M., Jarrad, F., and Main, E. (2015). Decreasing geographic bias in conservation biology. Conserv. Biol. 29, 1255-1256 doi: 10.1111/cobi.12589

Ceci, S. J., and Williams, W. M. (2011). Understanding current causes of women's underrepresentation in science. Proc. Natl. Acad. Sci. U.S.A. 108, 3157-3162. doi: 10.1073/pnas.1014871108

Cho, S. J., Na, S. W., Chung, H. Y., Kim, B. K., Kim, H. J., Hwang, J. I., et al. (2014). Analysis and Evaluation on Gender Budgeting in Korea (III). Seoul: Korean Women's Development Institute.

Conti A., and Visentin, F. (2015). A revealed preference analysis of $\mathrm{PhD}$ students' choices over employment outcomes. Res. Policy 44, 1931-1947. doi: 10.1016/j.respol.2015.06.009

Cooper, C. B., Dickinson, J., Phillips, T., and Bonney, R. (2007). Citizen science as a tool for conservation in residential ecosystems. Ecol. Soc. 12:11. doi: 10.5751/ES-02197-120211 barriers to diverse participation in conservation requires coordinated, mindful actions by individuals and organizations. We outline the development of an online network to facilitate connections among diverse scientists, educators, and practitioners separated by large expanses of ocean, and transfer of knowledge and expertise relevant to solving pressing conservation problems. We hope that the proposed network and other actions presented in this paper find widespread support, and that they might serve both as inspiration and guide to other groups concerned with increasing diversity and inclusivity.

\section{AUTHOR CONTRIBUTIONS}

Conceived focus group: LME and NSS. Organized focus group: LME and NSS. All authors listed, have made substantial, direct and intellectual contribution to the work, and approved it for publication.

\section{ACKNOWLEDGMENTS}

We thank the 4th International Marine Conservation Congress for hosting our focus group on Diversity and Inclusion in Conservation: A Proposal for a Marine Diversity Network in St. John's, NL, Canada in August 2016. NSS was supported by an Organization of American States Academic Graduate Scholarship. IMC was supported by a Natural Sciences and Engineering Research Council of Canada Discovery Grant. LME and LMC was supported by a Graduate Scholarship from the Mexican National Council for Science and Technology (CONACYT). DS was supported by a Liber Ero Post-doctoral Fellowship. AGB was supported in part by a grant from the Gordon and Betty Moore Foundation's Marine Conservation Initiative.
Douglas, L. R., and Veríssimo, D. (2013). Flagships or battleships: deconstructing the relationship between social conflict and conservation flagship species. Environ. Soc. 4, 98-116. doi: 10.3167/ares.2013.040107

Evans, C., Abrams, E., Reitsma, R., Roux, K., Salmonsen, L., and Marra, P. (2005). The neighborhood nestwatch program: participant outcomes of a citizen-science ecological research project. Conserv. Biol. 19, 589-594. doi: 10.1111/j.1523-1739.2005.00s01.x

Favaro, B., Oester, S., Cigliano, J., Cornick, L. A., Hind, E. J., Parsons, E. C. M., et al. (2016). Your science conference should have a code of conduct. Front. Mar. Sci. 3:103. doi: 10.3389/fmars.2016.00103

Fournier, A., and Bond, A. (2015). Volunteer field technicians are bad for wildlife ecology. Wildl. Soc. Bull. 39, 819-821. doi: 10.1002/wsb.603

Freeman, R., and Huang, W. (2015). Collaborating with people like me: ethnic co-authorship within the United States. J. Labor Econ. 33, S289-S318. doi: $10.1086 / 678973$

Fuller, R. A., Lee, J. R., and Watson, J. E. M. (2014). Achieving open access to conservation science. Conserv. Biol. 28, 1550-1557. doi: 10.1111/cobi. 12346

Giehl, E. L. H., Moretti, M., Walsh, J. C., Batalha, M. A., and Cook, C. N. (2017). Scientific evidence and potential barriers in the managementof brazilian protected areas. PLoS ONE 12:e0169917. doi: 10.1371/journal.pone.0169917

Ginther, D. K., Schaffer, W. T., Schnell, J., Masimore, B., Liu, F., Haak, L. L., et al. (2011). Race, Ethnicity, and NIH research awards. Science 333, 1015-1019. doi: $10.1126 /$ science. 1196783 
Green, S. J., Armstrong, J., Bogan, M., Darling, E., Kross, S., Rochman, C. M., et al. (2015). Conservation needs diverse values, approaches and practitioners. Conserv. Lett. 8, 385-387. doi: 10.1111/conl. 12204

Heenehan, H. (2014). The Power of Skype to Inspire a New Generation of Stem. Huffington Post - The Blog. Available online at: http://www. huffingtonpost.com/heather-heenehan/the-power-of-skype-to-ins_b 4549678.html (Accessed February 05, 2017).

Hind, E., Alexander, S. M., Green, S. J., Kritzer, J. P., Sweet, M. J., Johnson, A. E., et al. (2015). Fostering effective international collaboration for marine science in small island states. Front. Mar. Sci. 2:86. doi: 10.3389/fmars.2015. 00086

Kern, C. C., Kenefic, L. S., and Stout, S. L. (2015). Bridging the gender gap: the demographics of scientists in the USDA forest service and academia. Bioscience 65, 1165-1172. doi: 10.1093/biosci/biv144

Laurison, D., and Friedman, S. (2016). The class pay gap in higher professional and managerial occupations. Am. Sociol. Rev. 81, 668-695. doi: $10.1177 / 0003122416653602$

Madera, J. M., Hebl, M. R., and Martin, R. C. (2009). Gender and letters of recommendation for academia: agentic and communal differences. J. Appl. Psychol. 94, 1591-1599. doi: 10.1037/a00 16539

Martin, L. J. (2012). Where are the women in ecology? Front. Ecol. Environ. 10, 177-178. doi: 10.1890/12.WB.011

Meijaard, E., Cardillo, M., Meijaard, E. M., and Possingham, H. P. (2015). Geographical bias in citation rates of conservation research. Conserv. Biol. 29, 920-925. doi: 10.1111/cobi.12489

Moss-Racusin, C. A., Dovidio, J. F., Brescoll, V. L., Graham, M. J., and Handelsman, J. (2012). Science faculty's subtle gender biases favor male students. Proc. Natl. Acad. Sci. U.S.A. 109, 16474-16479. doi: $10.1073 /$ pnas.1211286109

Murphy, M. C., Steele, C. M., and Gross, J. J. (2007). Signaling threat: how situational cues affect women in math, science, and engineering settings. Psychol. Sci. 18, 879-885. doi: 10.1111/j.1467-9280.2007.01995.x

Notley, T. (2009). Young people, online networks, and social inclusion. J. Comput. Med. Commun. 14, 1208-1227. doi: 10.1111/j.1083-6101.2009.01487.x

Østergaard, C. R., Timmermans, B., and Kristinsson, K. (2011). Does a different view create something new? The effect of employee diversity on innovation. Res. Policy 40, 500-509. doi: 10.1016/j.respol.2010. 11.004

Parsons, E. C. M., Shiffman, D. S., Darling, E. S., Spillman, N., and Wright, A. J. (2014). How twitter literacy can benefit conservation scientists. Conserv. Biol. 28, 299-301. doi: 10.1111/cobi.12226

Pearson, A. R., and Schuldt, J. P. (2014). Facing the diversity crisis in climate science. Nat. Clim. Chang. 4, 1039-1042. doi: 10.1038/nclimate2415
Pimentel, D., Wilson, C., McCullum, C., Huang, R., Dwen, P., Flack, J., et al. (1997). Economic and environmental benefits of biodiversity. Bioscience 47, 747-757. doi: $10.2307 / 1313097$

Primack, R. B. (2001). Publish again in another language. Conserv. Biol. 15, 290-291. doi: 10.1111/j.1523-1739.2001.00201.x

Reuben, E., Sapienza, P., and Zingales, L. (2014). How stereotypes impair women's careers in science. Proc. Natl. Acad. Sci. U.S.A. 111, 4403-4408. doi: $10.1073 /$ pnas. 1314788111

Romero, C., and Andrade, G. I. (2004). International conservation organizations and the fate oflocal tropical forest conservation initiatives. Conserv. Biol. 18, 578-580. doi: 10.1111/j.1523-1739.2004.00397.x

Sardelis, S., and Drew, J. A. (2016). Not "pulling up the ladder": women who organize conference symposia provide greater opportunities for women to speak at conservation conferences. PLOS ONE 11:e0160015. doi: 10.1371/journal.pone.0160015 0160015

Steinpreis, R. E., Anders, K. A., and Ritzke, D. (1999). The impact of gender on the review of the curricula vitae of job applicants and tenure candidates: a national empirical study. Sex Roles 41, 509-528. doi: 10.1023/A:1018839203698

Stirling, A. (2007). A general framework for analysing diversity in science, technology and society. J. R. Soc. Interface 4, 707-719. doi: $10.1098 /$ rsif.2007.0213

Tallis, H., and Lubchenco, J. (2014). Working together: a call for inclusive conservation. Nature 515, 27-28. doi: 10.1038/515027a

Taylor, D. (2014). The State of Diversity in Environmental Organizations. Ann Arbor, MI: University of Michigan.

Wilson, J., and Biggs, D. (2016). Innovation and Research Suffer When Visa Rules Keep Scientists At Home. Observer. Available online at: http://observer.com/ 2016/10/innovation-and-research-suffer-when-visa-rules-keep-scientists-athome/ (Accessed February 05, 2017).

Wullum Nielsen, M., Alegria, S., Börjeson, L., Etzkowitz, Falk-Krzesinski, H. J., Joshi, A., et al. (2017). Gender diversity leads to better science. Proc. Natl. Acad. Sci. U.S.A. 114, 1740-1742. doi: 10.1073/pnas.1f16114

Conflict of Interest Statement: The authors declare that the research was conducted in the absence of any commercial or financial relationships that could be construed as a potential conflict of interest.

Copyright ( 2017 Smith, Côté, Martinez-Estevez, Hind-Ozan, Quiros, Johnson, Green, Cornick, Shiffman, Malpica-Cruz, Gleason Besch and Shiel-Rolle. This is an open-access article distributed under the terms of the Creative Commons Attribution License (CC BY). The use, distribution or reproduction in other forums is permitted, provided the original author(s) or licensor are credited and that the original publication in this journal is cited, in accordance with accepted academic practice. No use, distribution or reproduction is permitted which does not comply with these terms. 